\title{
FEMME FATALE E INTERTEXTUALIDAD, LA ONOMÁSTICA EN LOS POEMAS DE RAÚL GÓMEZ JAITTIN: MEDEA Y ELECTRA
}

Jorge Chen Sham

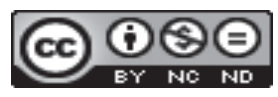

Doi: https://doi.org/10.15517/rfl.v46iEspecial.41713

URL: https://revistas.ucr.ac.cr/index.php/filyling/index 



\title{
FEMME FATALE E INTERTEXTUALIDAD, LA ONOMÁSTICA EN LOS POEMAS DE RAÚL GÓMEZ JAITTIN: MEDEA Y ELECTRA
}

\author{
FEMME FATALE AND INTERTEXTUALITY, THE ONOMASTICS \\ IN THE POEMS OF RAÚL GÓMEZ JAITTIN: \\ MEDEA AND ELECTRA
}

\author{
Jorge Chen Sham
}

\begin{abstract}
RESUMEN
El poeta colombiano Raúl Gómez Jattin (1945-1997), una de las voces más prístinas y encomiadas de la poesía colombiana de la segunda mitad del siglo XX, publica el poemario Del amor (1988), en donde reúne una compleja intertextualidad basada en la mitología y en la historia cultural de la humanidad. Me interesa analizar, en este artículo, dos poemas en los que Gómez Jaittin da rienda suelta a esa concepción decadentista de la femme fatale, revisitando así las figuras de Medea y de Electra. Su detallismo preciosista y la voluptuosidad, que tira hacia el sadismo, hacen que la visión de la mujer se acerque a la poesía del cubano modernista Julián del Casal, quien ya nos proponía en su poesía tal figuración de un erotismo malsano y punzante.

Palabras clave: Raúl Gómez Jaittin; poesía colombiana; Julián del Casal; decadentismo; femme fatale.
\end{abstract}

\begin{abstract}
The Colombian poet Raúl Gómez Jattin (1945-1997), one of the most pristine and praised voices of Colombian poetry of the second half of the 20th century, published the book Of Love (1988), where he gathered a complex intertextuality based on the mythology and in the cultural history of mankind. I am interested in analyzing, in this article, two poems in which Gómez Jaittin gives free rein to that decadent conception of the femme fatale, thus revisiting the figures of Medea and Electra. His attention to precious detail and voluptuousness, which leads to sadism, make the vision of women closer to the poetry of the modernist Cuban Julián del Casal, who already proposed in his poetry such a figuration of an unhealthy and pungent eroticism.
\end{abstract}

Keywords: Raúl Gómez Jaittin; Colombian poetry; Julián del Casal; decadent concept; femme fatale.

Dr. Jorge Chen Sham. Profesor de la Escuela de Filología, Lingüística y Literatura. Universidad de Costa Rica. Costa Rica. Miembro correspondiente de la Academia Nicaragüense de la Lengua y la Academia Norteamericana de la Lengua Española. Correo electrónico: jorgechsh@yahoo.com

Recepción: 20- 06- 19

Aceptación: 08- 01- 20 
Tanto el reconocimiento como la identificación de los fenómenos de intertextualidad dependen de la valoración de la interacción dialógica en la que entran, en cuanto, trozos, citas o evocaciones de un patrimonio cultural compartido; de ahí que la intertextualidad sea reconocida como un procedimiento de deconstrucción y de codificación al mismo tiempo (Amoretti, 1992, p. 7). Estos dos mecanismos (se reconocen y se identifican simultáneamente) permitirían develar los "sentimientos y actitudes" de ese conocimiento del mundo y de la experiencia en la que se insertan el autor y sus lectores, los cuales parten de sus referencias y lecturas más o menos explícitas. Porque el escritor las asume consciente o no conscientemente, la intertextualidad se define como esa percepción que el lector puede establecer entre un texto y otro(s) que le han precedido o le son sincrónicos (Riffaterre, 1980, p. 4). Así, el establecimiento y la codificación de estas relaciones se permiten, se provocan y se configuran a partir de recursos textuales (y gracias a ellos), a veces perceptibles y buscados, otras veces menos evidentes, que funcionan y se activan hasta que se les identifica ${ }^{1}$ En una suerte de ampliación de la capacidad receptiva del texto, solamente es posible este trabajo sobre la competencia del lector, para que se active toda la complejidad significativa de un texto literario; de lo contrario, pasan desapercibidas y no se desencadena su grosor o densidad de sentido cuya dinámica es un entrecruzamiento de acciones y reacciones (Peytard, 1983, p. 34).

Los trazos de la intertextualidad, indica Riffaterre, se circunscriben a procedimientos estilísticos que son regulados por imperativos textuales, con el fin de que los mecanismos de percepción / identificación se desencadenen. Un escritor puede ensayar estrategias para que esto ocurra; unas son más sutiles como las citas, las evocaciones o las paráfrasis; otros más complejas como las parodias o las alegorías; unas más visibles y al alcance del escritor como los epígrafes o la manera en que se nombran a los personajes. A este último recurso se le define con el nombre de onomástica, en la que se estudian los nombres propios de los personajes. El poeta colombiano Raúl Gómez Jaittin utilizó la onomástica para intitular muchos de sus poemas Del amor (1988), sobre todo los que retoman personajes de la mitología grecolatina. En el caso particular, él utiliza nombres propios como Medea o Electra, los cuales remiten directamente a figuras de la mitología griega, activando conscientemente el repertorio cultural, por un lado, y por otro, confrontando al lector hacia su desarrollo textual: ¿se trataría de una nueva versión?, ¿qué retoma del modelo?, ¿qué elementos innovadores aporta?

En semántica, el significado de los nombres propios es tarea fundamentalmente de análisis de la onomástica, que estudia el estatuto del nombre propio y su referencia individualizadora, "como un signo relacionado y condicionado por el contexto histórico cultural" (Iglesias Ovejero, 1981, p. 297). No se trata, entonces, de estudiar el significado denotativo o la etimología del nombre propio por sí mismo (su contenido lógico o etimológico, por ejemplo), sino:

a) su significado connotativo, "lo que comunica en virtud de aquello a lo que el lenguaje se refiere" (Berruto, 1979, p. 70);

b) su significado estilístico, "lo que se comunica sobre las circunstancias sociales del uso del lenguaje” (Berruto, 1979, p. 71); y,

En este caso, Riffaterre habla de fenómenos de intertextualidad aleatoria, porque dependen del reconocimiento: "La perception est donc aléatoire, puisqu'elle nécessite un certain dégré de culture, des lectures préalables" (Riffaterre, 1980, p. 5), con lo cual comprende que las citaciones, alusiones literarias, motivos y temas sean perceptibles e identificables. 
c) su significado afectivo, "lo que se comunica sobre los sentimientos y actitudes del hablante/escribiente" (Berruto, 1979, p. 71)2.

Con ello, el estudio de los nombres propios ganaría en precisión y daría cuenta de la complejidad manifiesta y evocada que la onomástica posee para desencadenar los mecanismos de significación. De esta manera, al privilegiar las relaciones entre nombrante y nombrado, las cuales dependen de operaciones de motivación y de personificación dentro de un contexto histórico y cultural particular, su proceso de significación conduce a la eponimia, por cuanto el "nombre representa la persona y define al personaje en una situación dada" (Iglesias Ovejero, 1981, p. 298). Lo anterior implica tomar en consideración que el nombre designa y es adecuado a su portador y que la motivación, fenómeno que, desde la lingüística saussureana, se asocia a la adecuación entre el nombre (significante) y la cosa (el significado), es completa y radicalmente significativa en materia de intertextualidad literaria, cuando esta se hace evidente e identificable. Así, los títulos de los poemas por analizar corresponden al nombre propio del personaje, el poeta los ha seleccionado como "portaestandarte" y "condensador" del texto, en una suerte de eponimia buscada y realzada. Se trata, en primer lugar, de una hipercaracterización, porque el nombre propio "es un signo analizable, conforme al principio de transparencia [redundante también]" (Iglesias Ovejero, 1981, p. 304), siguiendo el siguiente esquema:

$\begin{array}{lll}\text { Nombre propio } & \rightarrow & \text { Tipo hipercaracterizado } \\ \text { Individuo } & \rightarrow & \text { Archiclase de individuos } \\ \mathrm{X} \text { en el poema } & \rightarrow & \mathrm{X} \text { en el universo cultural }\end{array}$

La clave del mecanismo generalizador se encuentra en el título del poema, efecto de su eponimia, porque al yo poético se le atribuye un nombre propio, que el título exhibe y pregona, para que después se le caracterice según un universo cultural determinado. Si se trata de un nombre adecuado a quien lo porta y si sus actuaciones, comportamientos y conductas se ajustan y se identifican con el nombre propio que evoca (Iglesias Ovejero, 1981, p. 298), el texto exhibiría esta hipercaracterización buscada e identificable, "renvoyant, par une prédication plus ou moins explicite, à tel(s) autres référent(s)" (Meyer y Balayn, 1981, p. 196, la cursiva es del original).

Un escritor busca explorar y desarrollar esta motivación onomástica; lo puede hacer subrayando elementos paródicos e irónicos del nombre o buscando tales referentes con arreglo a los códigos culturales del mito grecolatino. Desde este punto de vista, el poeta colombiano Gómez Jaittin lo realiza remitiendo a un esquema que le viene de la tradición cultural de Occidente, el arquetipo de la femme fatale. En su seminal estudio sobre la literatura decadente, Mario Praz la identifica bajo el tópico de "la belle dame sans merci", "la bella dama sin misericordia o sin miramientos" (traducción propia) e insiste en que sus rasgos de "féminité tyrannique et cruelle" (Praz, 1977, p. 165) ya están presentes en el mito y la literatura grecolatinas. Disolutas para el orden masculino y, por lo tanto, de inspiración perturbadora, ellas "déclameront sur scène leurs passions sans limites, leurs luxurieuses amours, qui sèment la ruine et la perdition parmi les hommes" (Praz, 1977, p. 166). Pero a partir del Romanticismo, indica Praz, por la belleza y la voluptuosidad se asociarán a lo demoniaco (1977, p. 168), cuando precipita la caída del ser humano a los infiernos, para que

2 Retomamos el esquema analítico de Geoffey Leech (Semántica, Alianza Editorial, 1977), expuesto por Berruto (1979, pp. 70-71). 
Praz las defina como vampiresas (1977, p. 175). Su exotismo y sensualidad se imponen frente el espectáculo, cautivador y deslumbrante a la vez, de una voluptuosidad que solamente desea saciarse y doblegar al hombre. Esta es la perspectiva que selecciona Raúl Gómez Jaittin en su poema "Medea", cuando para vengar las ofensas de Jasón, ella exigirá sangre:



Medea afila los cuchillos en la cocina del palacio

con una fiera sonrisa torcida y desenfrenadamente loca

con una intención implacable y asesina ya puesta

a prueba cuando descuartizó e hirvió en una olla

a su padre el rey de la nativa tierra bárbara ${ }^{3}$ (v. 5).

Hace tres días que envenenó los regalos que enviara

a su rival la desdichada princesa prometida a Jasón

Son tóxicos quemantes que destrozarán sus carnes

traídos por Medea furtivamente desde la Cólquide (2004, p. 122).

El poema introduce los preparativos de Medea para acabar con sus hijos; la perspectiva del poeta colombiano es, entonces, la premeditación de su venganza con la insistencia en el afilamiento de los cuchillos. Los cuchillos utilizados son los de cocinar, con lo cual evidencia esa equiparación con el destazamiento de animales, para subrayar lo macabro de la escena futura. Ahora bien, la perspectiva de la voz poética aclara tanto la conmoción psicológica como la perturbación anímica, que sirven para introducir la escena de castigo y de muerte, la metonimia del verso 2 "con una fiera sonrisa torcida" corresponde a la evaluación siguiente de su estado mental: "[está] desenfrenadamente loca / con una intención implacable y asesina" (vv. 2-3). Observemos ambos núcleos nominales, "una fiera sonrisa torcida" y "una intención implacable y asesina" señalan no solo rasgos físicos sino también morales de una mujer alterada y fuera de sí; la doble adjetivación ya apunta hacia una descripción de la femme fatale. Al presentarla de esta forma, el poema caracteriza el lado sanguinario y bestial, fuera de lo humano de Medea, al tiempo que los versos 4 y 5 dan cuenta de su premeditada inclinación a lo truculento, al ensañarse primeramente sobre su propio padre. En su versión de Cartas de las heroínas, Ovidio hace que ella sea consciente de que, por amor, se ha entregado y ha dejado su patria: "Traicioné a mi padre, abandoné mi reino y mi patria y sobrellevé como regalo el poder estar exiliada, mi virginidad fue botín de un bandido extranjero" (1994, p. 110). En los mismos términos, se encuentra en la versión de Séneca de la siguiente manera, muy sucinta por cierto: "E Giásone ha potuto far questo? Dopo avermi strappata a mio padre, alla mia patria, al mio regno, è così crudele da abbandonarmi sola in una terra straniera?" (2006, p. 209) ${ }^{4}$. En la versión que serviría de modelo hipotextual, la de Eurípides, Medea se lamenta de su repudio y de su expulsión por parte de Creonte y, cuando se encuentra con Jasón, le espeta de la siguiente manera:

[...] y a la serpiente que guardaba el vellocino de oro, [...] la maté e hice surgir para ti una luz salvadora. Y yo, después de traicionar a mi padre y a mi casa, vine (en tu compañía) a Yolco en la Peliótide, con más ardor que prudencia. Y maté a Pelias con la muerte más dolorosa de todas, a manos de sus hijas, y aparté de ti todo temor (1991, p. 230).

3 Como habrá visto el lector, Gómez Jaittin suprime la puntuación en sus poemas. No se trata de ninguna errata o descuido de nuestra parte.

$4 \quad$ Cito por la única traducción de las tragedias de Séneca que he encontrado, con versión al italiano. El hecho de reproducir lo que exponen otras versiones de Medea radica en la necesidad de comprender la novedad introducida por el poeta colombiano. 
En ningún momento, en estas tres versiones, ni tampoco en Las Metamorfosis de Ovidio, Medea asesina a su padre, mucho menos lo descuartiza como lo hace Gómez Jaittin en su versión del mito; ella lo traiciona eso sí, y el texto de Ovidio habla abiertamente de lo que genera esta culpa:

¿Entregaré a traición el reino de mi padre, y con mi ayuda se salvará no sé qué advenedizo, para que, sano y salvo gracias a mí, sin mí largue las velas al viento y sea esposo de otra y yo, Medea, quede para el castigo? (2004, pp. 424-425).

Así, ella mata por amor, lo cual ahora justifica que lo haga en la tragedia de Eurípides con sus hijos en un acto de despecho, forzada por la situación inicial de la tragedia.

Ahora bien, en su retrato inicial, Gómez Jaittin insiste en las abominaciones de Medea con este ensamblaje sádico que hace entre dar muerte a su padre y cocinar sus miembros como si fuera una carnicera espeluznante. Los "cuchillos en la cocina” y la "olla" son los instrumentos de su sórdida apetencia de venganza / muerte, mientras que las acciones, "descuartizó" e "hirvió" (v. 4), auguran un mismo desenlace para los hijos. En estos preparativos, ella también "cocina" su plan de venganza, lo maquina, y para ello, entre los versos 6 y 9, se agrega como parte de este el envenenamiento a su rival, cuyo poder destructor también implica unos "tóxicos quemantes" (v. 8). La versión de Gómez Jaittin hace desaparecer la parte correspondiente a la pasión exacerbada, al odio que en este momento se apodera de Medea, para que se subraye el hecho de que se trata de un plan consciente de venganza. La versión de Ovidio en Cartas de las heroínas tiende más a justificar esta locura y despecho, de manera que expone las razones por las que termina con sus hijos, al explicitar, como también lo realiza Eurípides, lo que sucede en su fuero interior. Gómez Jaittin insiste en su plan premeditado y que el ciclo de violencia hubiera comenzado cuando cometió el parricidio y lo ha cocinado como si fuera una caníbal, que se sacia de los despojos humanos.

Sin embargo y, diferenciándose de Eurípides, en la segunda parte del poema, el poeta colombiano no insiste en el tormento interior de Medea, en sus dudas; Gómez Jaittin no explicita su estado mental para enfocarse solamente el premeditado plan de venganza:



La explícita referencia del verso 10 implica reconocer, no solo el modelo intertextual en el que Medea aparece como el arquetipo de la asesina de sus propios hijos por despecho de amor (este sería el rasgo eponímico), sino que también la voz poética sanciona moralmente su conducta, al categorizarla como "la asesina". Gómez Jaittin se olvida de la estratagema de los niños, que llevan los presentes a la princesa, entre ellos oro y prendas. Ahora bien, sigue actualizando el modelo cuando insiste en su premeditación y en su conducta desviada, cuando "de la cocina a la alcoba" (v. 11) se sigue preparando para cometer su crimen. En su poema, 
el poeta colombiano amplía el radio de acción de su venganza a la alcoba, en donde no solo esconde los cuchillos en el lecho amoroso (lo que en Eurípides es un asunto que no se muestra al público y se ventila dentro de palacio), sino además se acicala y embellece su cuerpo. Lo que Gómez Jaittin suprimió por un lado, lo adiciona por otro, para que la hermosa mujer se prepare para la matanza: se acicale y embellezca su cuerpo. El contraste inicial raya en la ironía, cuando los "cuchillos" se esconden "bajo los cobertores blancos / de lana virgen traída de Micenas y Rodas" (vv. 13-14), en esa alusión a la inocencia de los corderos sacrificados, que serán los hijos, por medio de la pureza representada por el color blanco y el posible contraste blanco / rojo, del sacrificio. Todo ello hace que tanto la "cocina" como la "alcoba" sean un escenario de muerte, dentro de unas relaciones malsanas, que Gómez Jaittin ahora desarrolla al mostrar el cuerpo voluptuoso de Medea. Toda esa retórica preciosista, enfocada en el "tocado de perlas y amatistas" (v. 15) y en "los pliegues de la pesada túnica / cosida con hilos refulgentes de oro asirio" (vv. 20-21) hablan de los preparativos de su cuerpo, de su falta de apego a la realidad (la distorsión que ocurre para que no pondere su amor de madre) y de su ceguera apasionada.

Ella se embellece y, adornándose también, se prepara física y emocionalmente para su sanguinario acto. La voluptuosidad de la descripción en Gómez Jaittin, de mirarse en el espejo "con impavidez / y despreocupación de lo terrible que trama" (vv. 18-19), es sinónimo de que las fronteras entre la sensualidad del cuerpo y la gratificación por lo escabroso y la sangre ya se han abolido. Es más, el verbo "tramar" adquiere su sentido completo, cuando se trata aquí de la fiera que acecha a su presa. El poeta colombiano asimila, entonces, a Medea a los felinos depredadores, tal y como sucede en este desenlace del poema:

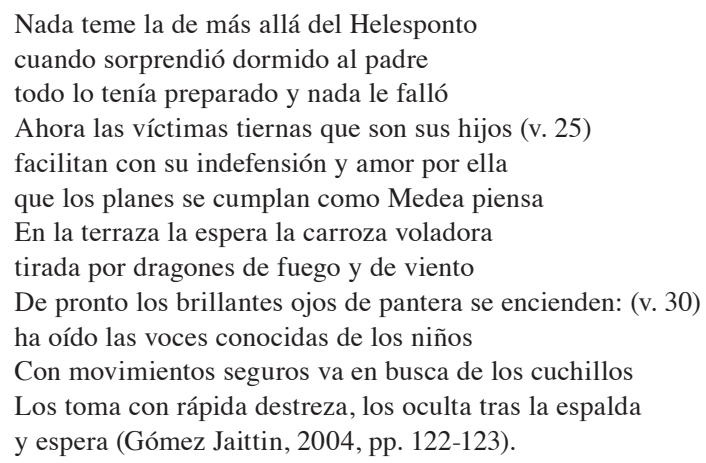

En su desenlace, Gómez Jaittin sube el ritmo del poema con frases verbales y adverbios que denotan el movimiento rápido de la escena. Todo se precipita para su final, de acuerdo con "los planes" (v. 27) de Medea. Por su parte, en Eurípides, es el coro quien anuncia horrorizado el desenlace por venir de la siguiente manera:

\footnotetext{
Antístofa 2.a.

También lloro tu dolor, desdichada madre de hijos, porque vas a matar a tus criaturas por un lecho nupcial que tu esposo ha traicionado sin razón, para compartir la vida con otra esposa. (El pedagogo regresa con los niños.) (1991, p. 249).
}

En la Medea de Eurípides, es tanta la presión de esos ojos inocentes de los niños que ella no puede soportar, para dudar y vacilar de funesto plan y, de este modo, titubear ante la idea del asesinato, con lo cual se ofrece el estado de los "sentimientos encontrados" en la madre: 
Vosotros no veréis más a vuestra madre con vuestros queridos ojos, pues estáis a punto de cambiar a otra forma de vida.

¡Ay, ay!, ¿por qué me miráis con vuestros ojos, hijos? ¿Por qué sonreís, como si fuese vuestra última sonrisa? ¡Ay, ay! ¿Qué voy a hacer? Mi corazón desfallece, cuando veo la brillante mirada de mis hijos. No podía hacerlo. Adiós a mis anteriores planes. Sacaré a mis hijos de esta tierra (1991, p. 250).

Dos supresiones y adiciones son obvias entre las dos versiones: del modelo euripideano, los ojos inocentes de los niños y el cambio momentáneo de su plan; la variante al modelo en Gómez Jaittin pondera la resolución meditada y planeada de tomar venganza, para que, en la metonimia del verso 30, "los brillantes ojos de pantera se encienden", no corresponda tanto el desequilibrio mental que Eurípides propone en la vacilación de Medea, como la representación de la fiera que se abalanza sobre las "víctimas" (v. 25) inocentes, del depredador que desea con ansia la vida de los inocentes niños. La avidez de sangre se une a ese manejo de los cuchillos por parte del experto carnicero, que el verso 33 subraya ("Los toma con rápida destreza"), con el fin de que, en ese cierre, inesperado y abierto, se prolongue la frenética acechanza y el desenfreno sanguinario de quien desea sangre y se desate la violencia motivada por su pasión (García del Paso, 2004, p. 24). Gómez Jaittin termina allí su poema, con lo cual el lector podría completar su versión con lo que indica Eurípides, quien nunca pone de primera mano esta matanza sino en el interior de la casa-palacio.

No hay, entonces, tragedia humana ni fatal destino en la "Medea" de Raúl Gómez Jaittin; se trata de una femme fatale que, fría y calculadora, planea el crimen, cuya mirada felina espanta por sus ojos fuera de sí. La voz poética toma así distancia y presenta su figura hipnótica y vengativa, sin que sepamos nada de su pasión; sus celos enfermizos o su ciega venganza que achaca a Jasón por haberla abandonado y traicionado de esta manera. Lesky plantea que la Medea de Eurípides es demoníaca, al ser asesina de sus propios hijos (1973, p. 171), pero se le olvida que su despecho y su sed de venganza vienen del hecho de que Jasón la haya repudiado y que Creonte la quiera expulsar de la ciudad; es decir, hay atenuantes para que, en esa vorágine de pasiones, ella quiera convertir su oprobio en venganza (Lesky, 1973, p. 173). Pero la versión de Gómez Jaittin omite esto, para que aquello que pudiera justificar a la mujer despechada desaparezca de la escena del mito y se concentre en esta carnicería premeditada. Seleccionar del texto mayor de Eurípides este fragmento de su locura asesina, olvidando sus lamentos y su anagnórisis, desemboca en el desarrollo de la figura de la mater horribilis en el poeta colombiano, aquella que inmola y destruye a sus propios hijos.

El mismo procedimiento de desvío del modelo se encuentra en el poema "Electra", en donde la abnegada y solícita hermana tiene razones ocultas para conminar también a su hermano Orestes para que los dos tomen venganza. La escena que catapulta Gómez Jaittin es también la versión de Eurípides, pero no reinterpreta todos los elementos según esta versión del mito, más bien los trastoca. En Eurípides, al inicio, Orestes le confiesa a Pílades su resolución cuando llega a su patria: "Acabo de llegar [...] para cobrar su crimen a los asesinos de mi padre" (1995, p. 292) y se encuentra a una desconocida con un cántaro, ella viene del pozo y entablan conversación. Lo primero que se subraya para los extranjeros es su doloroso lamento y su demacrado físico; al respecto indica Electra: "que mi cabeza y pelo están rapados a la manera escita" (1995, p. 297), para que su esposo ni la vuelva a ver en la cama. Momentos después, en honor a la hospitalidad, su esposo los recibe en su choza y se realiza el reconocimiento gracias al anciano pastor que identifica a Orestes; entonces, Electra puede interpelar a su hermano con la elaboración de su plan de venganza: 
Orestes. -Y ¿cómo mataré a aquélla y a éste en el mismo sitio?

Electra. - Yo te prepararé el asesinato de la madre.

Orestes. - Sí, que el de aquél seguro que lo dispondrá bien la suerte.

Electra. - Que la suerte, que es una, nos haga a nosotros dos este servicio (1995, p. 313).

Electra persuade a su hermano a tomar fuerzas apelando a los designios de los dioses, lo conmina a tomar la sangre de su madre y a cometer el asesinato de Clitemnestra. Las palabras de Electra son las que Gómez Jaittin reproduce en el verso 6. El poeta colombiano selecciona, en efecto, el momento después de realizado el asesinato e insiste en la culpabilidad de Electra, como en el modelo de Eurípides: "Aquí Electra no solamente induce al hermano a perpetrar el crimen, que el joven a la vista de su madre, ya no se vería con ánimos de cometer, sino que ella misma participa en el acto matricida, poseída del demonio [de su locura]" (Lesky, 1973, p. 200). Así empieza el poema, cuando ella ayuda a Orestes a lavar las pruebas del crimen; la escena comienza en el pozo donde se concertaron:

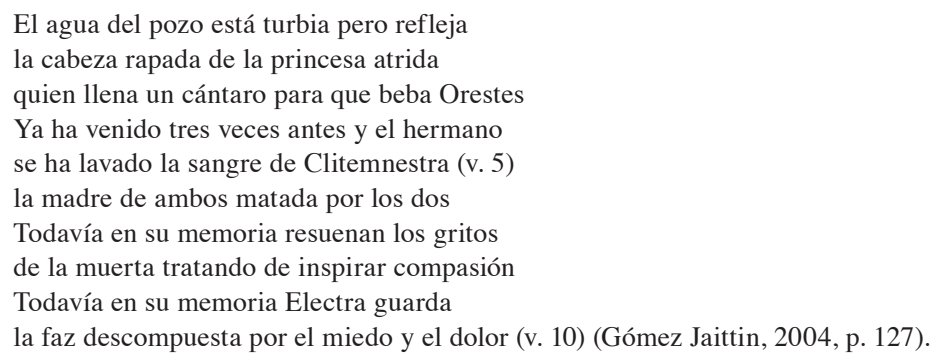

El motivo del agua reflejada, la del pozo, de esas aguas profundas que son espejo de la conciencia, describen la conmoción de Electra; el adjetivo "turbia", del verso 1, incide en esa atmósfera psicológica de un evento cuyas consecuencias apenas empiezan a esclarecerse al principio del poema. La cabeza rapada, signo del duelo, entra en equivalencia con el agua "turbia"; pero no sirve aquí para purificarse en ese ritual de lavarse la sangre las "tres veces" (v. 4), sino para ocultar, con ese retruécano del verso 6, el crimen cometido, que la voz poética explicita para atestiguar no tanto la verdad de los hechos como el lado truculento y premeditado de los matricidas 5 : "la madre de ambos matada por los dos". Del verso 7 al 9, la voz poética se acerca a la conciencia de Electra, de manera que tal relación sinecdótica entre "pozo" y conciencia empieza por aclararse en el recordatorio de toda ausencia de conmiseración y de sentimientos encontrados.

Recordemos que en el modelo euripideano, Orestes acaba primero con Egisto y, con la estratagema de estar en periodo de alumbramiento, Electra manda llamar a su madre a su seno. Clitemnestra llega y entre ellas dos se plantea un fuerte careo, en términos clásicos, un agón que Gómez Jaittin suprime, para que el hecho esté consumado al inicio del poema, mientras que, en Eurípides, Electra recrimina así a su madre y la hace entrar en la choza en donde se ejecutará el crimen:

La cesta está preparada y afilado el cuchillo que mató al toro, cerca del cual vas tú a caer herida. Vas a desposar, también en el hades, al hombre con quien dormías en vida. Éste es el favor que yo voy a hacerte, esta es la satisfacción que tú vas a pagarme por mi padre (1995, p. 331).

$5 \quad$ Recordemos que el término parricida se utiliza tanto para el padre o para la madre; Gómez Jaittin selecciona otro como veremos más adelante. 
Llama poderosamente la atención dos cosas: la sed de venganza por parte de Electra quien planifica su plan y hace venir a su madre al lugar de su muerte, y el cuidado puesto en el acto de la preparación del cuchillo, que aparece en "Electra" pero no en "Medea" de Eurípides; se trata de una clara inversión del motivo, para que en ambos poemas de Gómez Jaittin, la venganza se tome con cuchillos carniceros y se exponga la sed de sangre.

Ahora bien, en el poema de Gómez Jaittin, entre la determinación de Electra y su posterior "turbación" podría jugarse un desfase, que el poeta colombiano capta magistralmente, subrayando el corazón endurecido en la imagen de la madre "tratando de inspirar compasión" (v. 8) frente a la "la faz descompuesta por el miedo y el dolor" (v. 10) dentro de un paralelismo de contrastes que recuerda, rápidamente y con trazos escuetos, la escena del crimen en Eurípides. Los remordimientos y la culpa podrían, entonces, desarrollarse ante una Electra que podría tomar conciencia del acto cometido ante el pozo que le devuelve como imagen especular el trabajo de conciencia, o en términos clásicos, de anagnórisis ante el hecho de sangre cometido. Sin embargo, la segunda unidad del poema de Gómez Jaittin desmentirá categóricamente esta posibilidad, cuando empieza con el adverbio adversativo "mas":

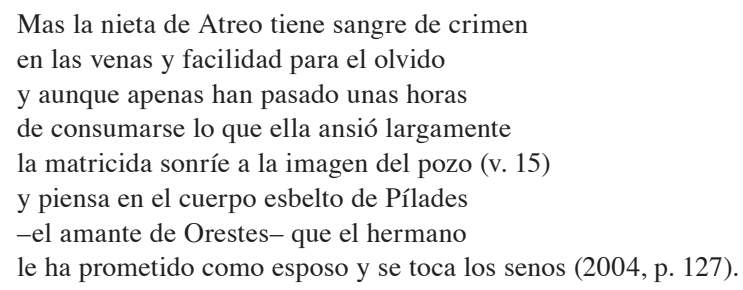

La voz poética no toma distancia moralmente; en el verso 15 la llama "matricida" e insiste en el triste destino de su sangre atávica, que la ha impulsado a cometer crímenes abominables, planteando así su responsabilidad moral. De nuevo se insiste en el crimen premeditado y calculado, al tiempo que, en el verso 15, ella "sonríe a la imagen del pozo" en una complicidad perturbadora para el lector, porque esa sonrisa es síntoma de su perversidad y de su escondido plan. Su reflejo desemboca en la inversión de la figura de Electra, porque ya no actúa como en el modelo de Eurípides, en donde instiga a su hermano por el deber de vengar a su padre según las leyes griegas. Todo lo contrario, devela ahora tanto su inspiración sádica como la mórbida pasión que corroe su alma; la gratificación erótica en el hecho que "se toca los senos" pensando en "el cuerpo esbelto de Pílades" (v. 16), señala impúdicamente la voz poética, desmiente cualquier respeto de normas sociales, para conducirnos al terreno de las pasiones humanas, tal y como señala Lesky en el caso de la versión de Eurípides, en donde la intriga obedece a ellas, las pasiones, solamente: los celos y la envidia. La doble anagnórisis con la que cierra el poema, por un lado en la sonrisa gratificante de Electra tocándose los senos y, por otro lado, la del lector que descubre la existencia de otro posible móvil para la muerte de Clitemnestra, conduce a la misma maestría técnica que Lesky encontraba en Eurípides en este tipo de construcción: "la riqueza del movimiento psicológico [...] corresponde a la acción externa" (Lesky, 1973, p. 207) y su paso hacia una interna que perturba a los actores de un drama más que humano. La inversión es radical en relación con el modelo de Eurípides, pues después de haber cometido el crimen, el coro en Eurípides atestigua que la madre "ha muerto ha muerto a manos de sus hijos" (1995, p. 332, la cursiva es del texto), mientras el corifeo los señala de la siguiente manera: "Mas helos aquí que ponen su pie fuera de la casa teñidos 
con la sangre reciente de su madre" (1995, p. 332). Orestes se echa toda la culpa; pero Electra, consecuentemente con su venganza, le increpa aceptando también su propia responsabilidad:

Electra. - Hermano, sí, deplorable en exceso, pero yo soy culpable. ¡Pobre de mí! Me consumí en odio contra esta mi madre que me parió.

Coro. - iAh, qué suerte, madre, qué suerte la tuya que pariste vengadores y sufriste desdichas sin límites a manos de tus hijos! [...] (1995, p. 333, la cursiva es del texto).

Ante el horror que expresa el coro, frente a ese dilema de vengar al padre y matar a la madre, de responsabilidad familiar pero también de sanción moral, ambos hermanos toman conciencia de sus actos y se lamentan de su amargo destino:

Orestes. -Oh Febo, invisible es la justicia que cantaste, pero bien visibles los dolores que has cobrado; ;me has dado un lecho de asesino lejos de la tierra griega! ¿A qué otro pueblo marcharé? ¿Qué huésped, quién que sea piadoso pondrá sus ojos en mi rostro de matricida?

Electra. - ¡Ay, ay de mí! Y yo, ¿adónde?, ¿a qué coro, a qué boda marcharé? ¿Qué esposo me aceptará en su cama nupcial? (1995, p. 333, la cursiva es del texto).

Por ser asesinos de su propia madre, ambos hermanos son conscientes de que las leyes sociales y humanas les impedirán llevar una vida tranquila y sosegada; más bien, el desprecio y su odio recaerán sobre ellos. Los “matricidas” deben expiar su culpa y, es por ello, que Cástor se aparece a ambos hermanos con el oráculo de los dioses:

Mas es fuerza resignarse y desde ahora has de cumplir lo que Moira y Zeus han decretado sobre ti. Entrega a Electra a Pílades como esposa y abandona Argos. No te está permitido poner el pie en esta ciudad ahora que has matado a tu madre (Eurípides, 1995, p. 335).

Por designio de los dioses, Orestes debe separarse de su amante y compañero; pero en la versión de Gómez Jaittin, la inversión del desenlace del mito es total, cuando se descubre otra motivación de Electra para empujar a su hermano hacia el crimen perfecto: neutralizarlo como rival. Por lo tanto, la sangre derramada y la sensualidad abyecta se dan la mano y desenmascaran la naturaleza pérfida y perversa de Electra en un movimiento que nos descubre su sadismo e intenciones retorcidas, mientras que, Orestes ya no es un "juguete del azar" (Lesky, 1973, p. 205), sino de los caprichos de su hermana.

A la luz de lo anterior, el arquetipo de la femme fatale se devela en toda fuerza inaudita. De "l'idole sanguinaire et implacable" (Praz, 1977, p. 201) en Medea, pasamos al placer indisoluble de la sangre para que se escondan "amours brûlées et des désir irrassasiés" (Praz, 1977, p. 202) en Electra.

Ahora bien, desde el punto de vista de la intertextualidad, habría que repensar el grado de información semántica que la nueva versión (la de Gómez Jaittin) redinamiza, pues en los dos casos el poeta colombiano suprime y adiciona a la vez:

Cuadro 1. Medea

\begin{tabular}{ll}
\hline Eurípides & Gómez Jaittin \\
\hline Palacio & Cocina-dormtorio (espacio) \\
\hline Cuchillos & Cuchillos afilados (instrumento) \\
\hline Venganza & Venganza-carnicería (móvil) \\
\hline Odio-locura & Odio-locura (sentimiento) \\
\hline Abandono-repudio- expulsión & (causa) \\
\hline
\end{tabular}


En el Cuadro 1, queda claro cuál es la información suprimida y cuál es la agregada por parte de Gómez Jaittin, para que en el poema del colombiano Medea se presente como la sanguinaria vengadora de su oprobio; al no presentar ni sus lamentos, ni las causas de su estado psíquico-emocional, ni sus arrepentimientos in extremis, en Gómez Jaittin, Medea es una calculadora sin sentimientos. Ahora veamos el caso de Electra en el Cuadro 2:

Cuadro 2. Electra

\begin{tabular}{ll}
\hline Eurípides & Gómez Jaittin \\
\hline Camino-choza & Pozo (espacio) \\
\hline Orestes & Orestes (instrumento) \\
\hline Venganza & Eliminación del rival (móvil) \\
\hline Odio & Envidia (sentimiento) \\
\hline
\end{tabular}

En la Electra de Gómez Jaittin hay una intención oscura y perversa para que Orestes asesine a su madre, y es eliminarlo como rival, ya que sus gestos desenmascaran su maquiavélico plan, cuando desea eliminar a Orestes de su camino al objeto de su deseo; actúa por celos y envidia. Lo anterior permite que Raúl Gómez Jaittin se posicione frente a la femme fatale realizando unos retratos poéticos que exaltan la voluptuosidad perversa y una sensibilidad particular, que el poeta colombiano, entusiasta en esta imbricación entre la pulsión de muerte y de vida, reúne en sus homenajes a la femme fatale. Ahora bien, Medea siempre ha representado esta figura, pero Gómez Jaittin la descubre, con sorpresa y contraviniendo toda nuestra tradición occidental en Electra, destruyendo su figura de hija apegada a los valores patriarcales. ¿En dónde encuentra Gómez Jaittin este impulso para provocar de esta manera revisitar los mitos de Medea y Electra?

En la literatura decadente, la belle dame sans merci representa ese modelo que, en la poesía hispánica, tiene su máxima expresión en la figura de Salomé, en quien Mario Praz encuentra "cet emportement frénétique, cette large et puissante débauche qui ne craint pas de méler le sang et le vin, ces deux pourpres" (1977, p. 178), los cuales provocan su danza macabra. El poeta cubano Julián del Casal (1863-1893), de quien se ha estudiado su propensión a lo mórbido de la enfermedad y de la muerte, así como a las imágenes del cuerpo putrefacto en las que el deseo se sostiene y es a la vez trasunto de la corrupción del alma (Montero, 1993, pp. 147-148), hace aflorar retratos femeninos llenos de voluptuosidad y de perversión. En su segundo poemario, Nieve (1892), Casal escribe un soneto dedicado a la "Salomé" bíblica. Contrasta la "mirada grave, barba canosa y extenuado pecho" (1993, vv. 5-6) de su padrastro, para que el poeta cubano se fije, sobre todo en su vestimenta deslumbrante y preciosista en los dos tercetos:

Delante de él, con veste de brocado

estrellada de ardiente pedrería, (v. 10)

al dulce son del bandolín sonoro.

Salomé baila y en la diestra alzado, muestra siempre, radiante de alegría, un loto blanco de pistilos de oro (1993, p. 173).

El efecto cromático de su sensual vestido se acompaña, indirectamente, del reflejo especular de los ojos de quien la mira, "ardiente" de deseos; el intertexto bíblico sugiere el baile voluptuoso, la mirada hipnótica de los espectadores y la belleza de Salomé, de modo 
que el detalle del "loto blanco" (v. 14) anuncie así el trofeo que pedirá a cambio en su sed de venganza. El lector espera con suspenso este desenlace de la historia, que el poema atisba y presagia, so pena de no ratificar el mito de la impúdica Salomé. La asociación entre la pedrería preciosista de su vestido y el acto criminal, que demandará, ya prefigura un alma despiadada y vengativa, como en el caso de la Medea de Gómez Jaittin. Lo suntuario y los adornos que acompañan el cuerpo femenino enaltecen y realzan lo que la naturaleza ha proporcionado; no se habla de su belleza física porque el mito la ha expuesto así y aquí se ofrece como presupuesto previo para el lector dentro de la intertextualidad.

Veamos el siguiente ejemplo también de Casal en el mismo poemario. Retoma la figura de Elena, quien, desde las murallas de Troya, observa tanto el incendio en un teatro de guerra, así como los cuerpos de los guerreros caídos; Casal lo expone en el primer cuarteto: "Luz fosfórica entreabre claras brechas / en la celeste inmensidad, y alumbra / del foso en la fatídica penumbra / cuerpos hendidos por doradas flechas" (1993, p. 234, vv. 1-4). El incendio de la noche ilumina los cuerpos dentro de un contraste de claroscuro que rápidamente la voz poética descubre como de "escombros hechos" (1993, v. 8); son las ruinas de la muerte que se avecina sobre los guerreros inmolados en la contienda. Ahora bien, Casal vuelve en los dos tercetos sobre la mirada de Elena, la cual contempla la escena del desastre:



El adjetivo utilizado para caracterizar a Elena ante los desastres de la guerra es altamente significativo; se trata de "indiferente" (v. 12), mientras que su mirada se vuelve hacia el horizonte sin que muestre la menor identificación y conmiseración con lo que sucede a su alrededor; el adjetivo "lívido", referido al "horizonte" (v. 13) permite, sin embargo, calificar también su semblante. Dos cosas se imponen, "lívido", por su origen latino, se relaciona con "[a]moratado, azulado", es decir, con el color de la muerte; pero en su sentido popular, se utiliza "por pálido", indica García-Pelayo y Gross (1976, p. 633), lo cual conduce a una ambigüedad que es necesaria explicitar. Si su cara refleja la muerte, la Elena de Casal estaría congraciándose y aceptando la destrucción que se produce ante sus ojos; si estuviera pálida estaría en choque. Como buen conocedor de las posibilidades del lenguaje que poseía Casal, me inclino por la primera explicación; Helena, a manera de una Nerón, se regodea y se alegra de tal incendio y destrucción, para que se muestre un rasgo que el mito grecolatino no explora: su carácter perverso. La sorpresa es total en el lector de Casal en este desenlace que hace de Elena de Troya una mujer cruel que se regodea ante la desgracia ajena y las muertes que ella ha acarreado.

El tercer ejemplo y final también se encuentra en el mismo poemario y se trata del soneto dedicado a la figura de Galatea. La oposición entre Polifemo y Galatea se asegura en la inocencia y la belleza que la ninfa representa, frente al cíclope que la asecha y acecha a la vez. La escena imaginada por Casal es la del cíclope que la mira en su desnuda belleza y cae en el éxtasis. Toda nuestra tradición ha opuesto la belleza de la ninfa frente a la fealdad del cíclope; pero también, el mito siempre ha insistido en que quien cae en el embeleso es Polifemo frente a las gracias de la recata e inocente ninfa. Pues bien, veamos el desenlace ofrecido por Casal en los dos tercetos: 




Otra vez, el desenlace sorpresivo quiebra nuestros esquemas culturales y la representación de la ninfa, y hace cuestionar la versión del mito; el hipérbaton del verso 14 altera nuestra percepción de la escena para comprender que "la lujuria" es el sujeto de la oración y esta se refiere a Galatea; el furor amoris de toda nuestra tradición amorosa en el verbo "incendia" permite comprender que el objeto del deseo de Polifemo es la inocente y graciosa ninfa; pero ella es quien lo provoca conscientemente. Si la lujuria se refiere en tanto pecado capital al placer de la carne y al apetito carnal, el espectáculo ofrecido por Galatea no es tan inocente, porque ella lo "enciende" (permítaseme ser tan explícito aquí) no tanto en un juego de ingenuidad y gracia de una ninfa sino de perversión, porque ella se sabe observada. La "lujuria", sinécdoque de Galatea, está representada por ese cuerpo desnudo que se le ofrece al cíclope: ella no solo se le insinúa sino también hace que chispee su vista, en esa asimilación que otros críticos casalianos han visto entre el desear y seducir (Gutiérrez, 2005 p. 43).

En conclusión, el detallismo preciosista y la voluptuosidad de la mujer, que la impulsa hacia el sadismo, hacen que la poesía del cubano modernista Julián del Casal marque esa tendencia de la que podría nutrirse Raúl Gómez Jaittin, quien ya nos proponía en su poesía tal figuración de un erotismo malsano y punzante, macabro y retorcido, de inversiones al mito grecolatino con figuras femeninas impúdicas y fuertes. Su mediación sería, en este caso, el arquetipo de la femme fatale, que encontramos en los dos. Volviendo a la intertextualidad, no se trata de establecer una relación con Julián de Casal, no hay directamente en el poeta colombiano una cita o una referencia en sus poemas analizados que pueda servir de prueba, pero sí puede establecerse tal equivalencia a través del arquetipo analizado. La eponimia en ambos poetas latinoamericanos concluye en un desvío a la norma para que agreguen algo nuevo y supriman elementos pasivos y débiles de sus figuras femeninas. Ahora bien, en materia de referencias intertextuales, Gómez Jaittin sabe sacar provecho de las versiones que nos ofrece Eurípides, para seguir convocando, tal y como lo exponía Jacqueline de Romilly y resumía de esta manera: "la tragédie des passions" (1986, p. 110). En estos dos poemas de Jaittin que retoman simplemente el nombre propio del personaje, "l'onomastique littéraire a pour tâche de préciser les conditions spécifiques du fonctionnement de son objet dans le champ qui lui est propre" (Nicole, 1983, p. 235), en este caso, el del mito grecolatino. La Medea y la Electra de Gómez Jaittin no son pasivas, son dueñas de su destino en tanto mujeres que saben cuáles son los objetos de sus pasiones y de sus deseos.

\section{Bibliografía}

Amoretti Hurtado, M. (1992). Por una dialógica de la cultura. Aportes de Bajtín al pensamiento contemporáneo. Revista de Filología y Lingüística, 18(2), 7-8.

Berruto, G. (1979). La semántica. México, D. F.: Editorial Nueva Imagen.

Casal, J. (1993). Poesías completas y pequeños poemas en prosa (en orden cronológico). Miami: Ediciones Universal. 
Eurípides. (1991). Tragedias I. Madrid: Editorial Gredos.

Eurípides. (1995). Tragedias II. Madrid: Editorial Gredos.

García del Paso Carrasco, M. D. (2004). Mujer y Pietas: Transgresión femenina en Roma. En A. M. del Pino y G. Rodríguez Herrera (Eds.). Metáforas de perversidad: Percepción y representación de lo femenino en el ámbito literario y artístico (pp. 13-33). Las Palmas de Gran Canaria: Fundación Mapfre Guanarteme.

García-Pelayo y Gross, R. (1976). Pequeño Larosse Ilustado. París: Ediciones Larousse.

Gómez Jaittin, R. (2004). Amanecer en el valle del Sinú (Antología poética). Bogotá: Editorial Fondo de Cultura Económica.

Gutiérrez, M. A. (2005). Julián del Casal y Gérard de Nerval o la despiadada búsqueda de la gratificación del Deseo. En Luis A. Jiménez (Ed.), Julián del Casal en el nuevo milenio (pp. 33-55). Managua: PAVSA.

Iglesias Ovejero, A. (1981). Eponimia: motivación y personificación en el español marginal y hablado. Boletín de la Real Academia Española, 61(223), 297-349.

Lesky, A. (1973). La tragedia griega. (4 ed.) Barcelona: Editorial Labor.

Meyer, B. y Balayn, J. D. (1981). Autour de l'antonomase de nom propre. Poétique, 46, 183-199.

Montero, O. (1993). Erotismo y representación en Julián del Casal. Ámsterdam: Rodopi.

Nicole, E. (1983). L'onomastique littéraire. Poétique, 54, 233-253.

Ovidio. (1994). Cartas de las heroínas. Madrid: Editorial Gredos.

Ovidio. (2004). Metamorfosis. (6 ed.). Madrid: Ediciones Càtedra.

Peytard, J. (1983). La place et le statut du 'lecteur' dans l'ensemble 'public' (Annexe). Semen 1 (lecteur et lecture), Annales Littéraires de l'Universitè de Bésançon (pp. 29-41). París: Les Belles Lettres.

Praz, M. (1977). La chaire, la mort et le diable dans la littperature du XIXè siècle: Le romantisme noir. París: Éditions Denoël.

Riffaterre, M. (1980). La trace de l'intertexte. La Pensée, 215, 4-18.

Romilly, Jacqueline. (1986). La tragédie grecque. (4 ed.). París: PUF.

Séneca. (2006). Tutte le tragedie. Roma: Newton Compton Editori. 